\title{
Aptamer-Conjugated Magnetic Bead Pull Down and Detection of Human Growth Hormone Releasing Peptides from Serum and Urine by Mass Spectrometry
}

\author{
John G Bruno* and Taylor Phillips \\ Operational Technologies Corporation, San Antonio, USA
}

*Corresponding author: John G Bruno, PhD, Operational Technologies Corporation, 4100 NW Loop 410, Suite 100, San Antonio, TX 78229, ext. 4228, USA, Tel: +1-210-731-0015, E-mail: brunobiotech@gmail.com

\begin{abstract}
DNA aptamers were developed against human growth hormone releasing peptide (GHRP)- 6 and the major metabolite of GHRP-2 (pralmorelin) known as AA-3 (D-Ala-D( $\beta$-naphthyl)-Ala-Ala-OH) in $10 \%$ human serum or $50 \%$ human urine. The lead 5'-biotinylated candidate aptamers from ELISA-like microplate screening were conjugated to commercially available Dynal ${ }^{\mathrm{TM}}$ streptavidin-polystyrene-coated $2.8 \mu \mathrm{m}$ diameter magnetic (magnetite) microbeads (MBs) and used to "pull down" and purify or enrich for their cognate targets from buffer as well as undiluted human serum and urine. Aptamer binding was detectable at low ng levels in buffer, but not in serum or urine by the ELISA-like (ELASA) assay. Similarly, aptamer-MB pull down was detectable in buffer by electrophoresis in Coomassie blue-stained $20 \%$ polyacrylamide gels, but gel detection in serum and urine was compromised. In two cases, lead GHRP-6 candidate aptamers were shown to pull down an interfering protein in the vicinity of $50 \mathrm{kD}$ from serum by electrophoresis. AA-3 and GHRP-6 were pulled down using aptamer-coated MBs and detected in buffer, serum and urine by mass spectrometry (MS) in $81.25 \%$ (13 of 16 trials), thus attesting to the potential of aptamers for use in the detection of doping with these peptides in athletes. The $18.75 \%$ (3 of 16 trials) negative detection results by MS for aptamer-MB pull down trials were rectified when $5 \mathrm{X}$ more aptamer-MB reagents were added or when the aptamer-MBs were used in the body fluid matrices in which they were selected (i.e., the aptamers were placed in their intended chemical environments). The aptamer-coated MB pull down method is generalizable to enrichment and sensitive detection of other analytes in serum and urine as well using aptamers selected in these body fluid matrices.
\end{abstract}

\section{Keywords}

Aptamer, GHRP, Growth hormone, Magnetic bead, Peptide, Pull down

\section{Introduction}

Athletes who engage in doping for performance enhancement have become increasingly sophisticated in their strategies to avoid detection. Thus, it is no longer adequate to simply test for recombinant human growth hormone ( $\mathrm{hGH}$ ) or its induced longer-lived effector IGF$1[1,2]$. Some athletes are currently doping with a family of growth hormone releasing peptides (GHRPs) known to induce secretion of hGH (secretagogues) [3] which are delineated in Barroso, et al. [4]. Although, liquid chromatography-mass spectrometry (LC-MS) and immunoassay techniques already exist for detection and quantification of these GHRP and related peptide hormones [5-8], antibody development is well known to be hindered by a lack of immunogenicity by low molecular weight (MW) peptides which require conjugation to carrier proteins for antibody development. Nucleic acid aptamers are developed entirely in vitro and obviate the need for host animals or even cell culture [9]. In addition, some antibodies are known to exhibit imperfect batch-to-bath reproducibility [9-11] which may affect inter-laboratory reproducibility for testing labs. Aptamers do not suffer from lot-to-lot variations in composition, because their known DNA sequences can be precisely reproduced time and again by chemical synthesizers [9].

Thus, after consultation with GHRP experts at the World Anti-Doping Agency (WADA) about the most important GHRP targets, the authors sought to develop a set of high affinity and highly specific DNA aptamers to detect the major metabolite of pralmorelin or GHRP-

Citation: Bruno JG, Phillips T (2018) Aptamer-Conjugated Magnetic Bead Pull Down and Detection of Human Growth Hormone Releasing Peptides from Serum and Urine by Mass Spectrometry. Int J Med Nano Res 5:021. doi.org/10.23937/2378-3664/1410021

Received: March 15, 2018: Accepted: April 28, 2018: Published: April 30, 2018

Copyright: (c) 2018 Bruno JG, et al. This is an open-access article distributed under the terms of the Creative Commons Attribution License, which permits unrestricted use, distribution, and reproduction in any medium, provided the original author and source are credited. 
<smiles>C[C@H](N)C(=O)N[C@@H](Cc1ccc2ccccc2c1)C(=O)N[C@@H](C)C(=O)O</smiles>

AA-3 Metabolite of GHRP-2: D-Ala-D-( $\beta$-Naphthyl)-Ala-Ala-OH GMW = 357.47<smiles>C[C@H](NC(=O)[C@H](Cc1c[nH]c2ccccc12)NC(=O)[C@H](N)Cc1cnc[nH]1)C(=O)N[C@@H](Cc1c[nH]c2ccccc12)C(=O)N[C@@H](Cc1ccccc1)C(=O)N[C@@H](CCCCN)C(N)=O</smiles>

GHRP-6: His-D-Trp-Ala-Trp-D-Phe-Lys- $\mathrm{NH}_{2}$ Amine attached at C-terminus $\mathrm{GMW}=\mathbf{8 7 2 . 4 4 4}$

Figure 1: Structures and molecular weights of the target peptides.

Table 1: DNA sequences of the lead anti-GHRP aptamer candidates.

\begin{tabular}{|c|c|}
\hline Vame & ce $5^{\prime} \rightarrow 3^{\prime}$ \\
\hline AS-28F & $\begin{array}{l}\text { ATACGGGAGCCAACACCA-TCCTGCTTCATTCGCCCTTCCCCTGGCCACTCCCCTAATCCTCATTGTCAGTTATC } \\
\text { ITCCAGCC-AGAGCAGGTGTGACGGAT }\end{array}$ \\
\hline AU-23F & $\begin{array}{l}\text { ATACGGGAGCCAACACCA-CCATCCAGCTCATACGCTCCCCGACTTATTCAGCCATTCATTGGCACTAACCCTA } \\
\text { CCACCCCCC-AGAGCAGGTGTGACGGAT }\end{array}$ \\
\hline G6S-16F & 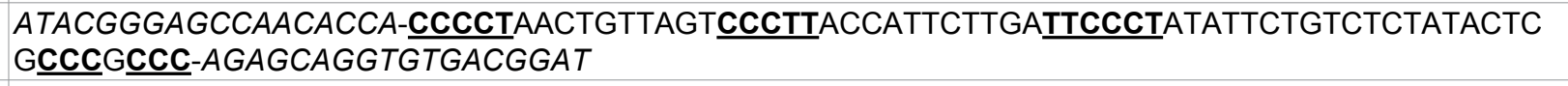 \\
\hline G6U-18R & $\begin{array}{l}\text { ATCCGTCACACCTGCTCT-GGGCGATAGGACGGGCTTTACTGCGTAACCGGCCGAGCAGAGAGGCTGGGCTC } \\
\text { GCCTCGAGTGC-TGGTGTTGGCTCCCGTAT }\end{array}$ \\
\hline
\end{tabular}

Notes: All sequences are written $5^{\prime}$ to $3^{\prime}$ from left to right. The italicized first 18 and last 18 bases constitute constant primer binding regions for PCR amplification of aptamers. The intervening middle 64 bases were randomized in the initial SELEX DNA template library. Underlined and bolded runs of $\mathrm{C}$ and $\mathrm{T}$ bases were common among three of the lead GHRP aptamers.

2 known as AA-3 and GHRP-6 (abbreviated G6 herein) whose structures and MWs are shown in Figure 1, because they had developed successful high-affinity and highly specific aptamers to several other physiologically active peptides previously $[12,13]$. The authors further sought to demonstrate the utility of the lead GHRP aptamers when attached to magnetic microbeads (MBs) to pull down, purify and enrich $[14,15]$ their cognate analytes from buffer, human serum and urine with validation by gel electrophoresis and mass spectrometry (MS) as reported herein.

\section{Materials and Methods}

Systematic evolution of ligands by exponential enrichment (SELEX) and aptamer secondary structure determinations

AA-3 (D-Ala-D( $\beta$-naphthyl)-Ala-Ala-OH) and GHRP-6 (His-D-Trp-Ala-Trp-D-Phe-Lys- $\mathrm{NH}_{2}$ ) were both synthesized by Genway Biotech (San Diego, CA) and purified to greater than $98.0 \%$ as assessed by reverse-phase HPLC. The peptides were dissolved and diluted up to $500 \mu \mathrm{g} /$ $\mathrm{mL}$ in sterile phosphate buffered saline (PBS, $\mathrm{pH}$ 7.2) conjugated to Dynal ${ }^{\mathrm{TM}}$ (Life Technologies, Inc., Carlsbad, CA) tosyl-M280 (2.8 $\mu \mathrm{m}$ diameter) MBs at a ratio of $40 \mu \mathrm{g}$ of peptide per $100 \mu \mathrm{L}$ of stock tosyl-MBs by virtue of having primary amines in their structures. Nine rounds of MB-SELEX DNA aptamer development were conducted according to previously published protocols $[1,2,12,13]$ except that the aptamers were either selected in $10 \%$ pooled human AB serum (Mediatech Inc., Cat. No. $35-060-\mathrm{Cl}$, diluted in sterile nuclease-free water) or $50 \%$ human urine (pooled from one of the author's families) to emulate the chemical environments in which the aptamers were intended to bind. After each round of SELEX, the presence of a $100 \mathrm{bp}$ aptamer PCR product in a $2 \%$ agarose gel stained with ethidium bromide was used to verify the SELEX process and enable progression to the next round. All DNA SELEX templates, primers as previously described $[1,2,12,13]$, and biotinylated candidate aptamers were synthesized at Integrated DNA Technologies, Inc. (IDT; Coralville, IA).

Round 9 GHRP aptamers were cloned into chemically competent $E$. coli using a GC (high Guanine-Cytosine content) cloning kit from Lucigen Corp. (Middleton, WI) and sequenced at Sequetech Inc. (Mountain View, CA) using proprietary high GC DNA sequencing techniques. The total of 142 unique individual DNA aptamers which resulted for the two GHRP targets (69 aptamer sequences for AA-3 and 73 sequences for GHRP-6) were synthesized as separate $5^{\prime}$-biotinylated oligonucleotide sequences and lyophilized at 4 nanomoles per well in individual wells of 96-well plates and purchased from IDT. Secondary stem-loop structures of the top four aptamers from Table 1 were determined by entering the individual DNA sequences into free internet UNAFold 
software on IDT's website (https://www.idtdna.com/ UNAFold) using $25^{\circ} \mathrm{C}$ and $145 \mathrm{mM}$ sodium as parameters.

\section{Direct ELISA-like or Enzyme-linked aptamer sorbent assay (ELASA)}

To determine relative affinity rankings for each of the candidate GHRP aptamer sequences, an ELASA $[1,2,13]$ was conducted by first immobilizing $250 \mathrm{ng}$ per well of the GHRP peptides in $100 \mu \mathrm{L}$ of $0.1 \mathrm{M} \mathrm{NaHCO}_{3}(\mathrm{pH} 8.5)$ overnight at $4{ }^{\circ} \mathrm{C}$ in covered, flat-bottom, polystyrene 96-well plates (Greiner Bio-One $\mathrm{GmbH}$, Frickenhausen, Germany; Cat. No. 655101). Plates were decanted and washed three times in $200 \mu \mathrm{L}$ of sterile PBS plus $0.001 \%$ Tween 20 (PBST). Wells were then blocked with $150 \mu \mathrm{L}$ of $2 \%$ ethanolamine in $0.1 \mathrm{M} \mathrm{NaHCO}_{3}$ for $1 \mathrm{~h}$ at $37^{\circ} \mathrm{C}$ and decanted, followed by three more washes with 200 $\mu \mathrm{L}$ of PBST. The unique 69 AA-3 and 73 G6 5'-biotinylated candidate aptamer DNA sequences from the round 9 pool (Table 1) were then added to their respective wells at 500 picomoles per well in $100 \mu \mathrm{L}$ of PBS and mixed at room temperature $\left(\mathrm{RT} ; \sim 25^{\circ} \mathrm{C}\right)$ on a rotary mixer for $1 \mathrm{~h}$. Wells were decanted and washed three times in $200 \mu \mathrm{L}$ of PBST for at least $5 \mathrm{~min}$ per wash with gentle mixing. One hundred $\mu \mathrm{L}$ of a 1:3,000 dilution of streptavidin-peroxidase (SAv-HRP; Thermo-Fisher, Waltham, MA; Product No. 21126) from a $1 \mathrm{mg} / \mathrm{mL}$ stock solution was added per well for 30 min at RT with gentle mixing. Wells were again decanted and washed three times with $200 \mu \mathrm{L}$ of PBST as before. One hundred $\mu \mathrm{l}$ of One-Component ${ }^{\oplus}$ ABTS substrate (Kirkegaard Perry Laboratories, Gaithersburg, MD), which had been equilibrated to RT, was added per well for $15 \mathrm{~min}$ at $\mathrm{RT}$, and reactions were halted by addition of $100 \mu \mathrm{L}$ of $1 \%$ SDS. Absorbance was quantified using a microplate reader at $405 \mathrm{~nm}$.

Identical ELASA technique was used for GHRP titration experiments except that $100 \mu \mathrm{L}$ of AA-3 or G6 containing $1,000 \mathrm{ng} / \mathrm{mL}$ each peptide in $0.1 \mathrm{M} \mathrm{NaHCO}_{3}$ was serial two-fold diluted in $100 \mu \mathrm{L}$ of $0.1 \mathrm{M} \mathrm{NaHCO}_{3}$ per well across a microtiter plate. No target was added to some wells to serve as background blanks and the 500 picomoles of each lead aptamer were added in 100 $\mu \mathrm{L}$ of PBS, undiluted human serum or human urine and 5 -biotinylated aptamers were allowed to bind for $1 \mathrm{~h}$ at RT with gentle mixing. Pooled and certified disease-free human blood serum and urine were purchased from Bioreclamation IVT, LLC (Hicksville, NY) for the ELASA titration and aptamer-MB pull down studies.

\section{Aptamer-MB pull down procedure}

One hundred $\mu \mathrm{l}(160 \mathrm{mg})$ or $500 \mu \mathrm{L}(800 \mathrm{mg})$ of stock Dynal ${ }^{\mathrm{TM}}$ streptavidin (SAv)-polystyrene-coated M280 $2.8 \mu \mathrm{m}$ diameter MBs (Thermo-Fisher Corp.) to be used per sample were washed twice in $1 \mathrm{~mL}$ of sterile phosphate buffered saline (PBS, pH 7.2) for $5 \mathrm{~min}$ per wash on a Dynal ${ }^{\top \mathrm{M}}$ MPC $^{\circledR}$ magnetic rack $[14,15]$. All four lead 5'-biotinylated DNA aptamers from Integrat- ed DNA Technologies, Inc. (Coralville, lowa, USA) were rehydrated at $\sim 2.2 \mathrm{mg} / \mathrm{ml}$ in sterile PBS and $100 \mu \mathrm{L}$ of aptamers were added per $100 \mu \mathrm{L}$ of stock SAv-MBs and mixed at room temperature (RT) for $1 \mathrm{~h}$ in sterile $1.7 \mathrm{~mL}$ microfuge tubes. Aptamer-5'-biotin-SAv-MBs (hereby referred to as aptamer-MBs) were collected on the Dynal $^{\mathrm{TM}} \mathrm{MPC}^{\circledR}$ magnetic rack for 2 min and washed 3 times in $1 \mathrm{~mL}$ of sterile PBS per wash. Aptamer-MBs were resuspended in their original volume of sterile PBS, stored at $4{ }^{\circ} \mathrm{C}$ and then used in pull down assays as follows. In initial studies, $100 \mu \mathrm{L}$ of stock aptamer-MBs were added per sample tube to $1 \mathrm{~mL}$ of sterile PBS, human serum or urine as indicated and spiked with $100 \mu \mathrm{g}$ of each GHRP target. In subsequent studies, the level of aptamer-MBs was increased to $500 \mu \mathrm{L}$ per sample tube with $100 \mu \mathrm{g}$ of each GHRP per microfuge sample tube in PBS, serum or urine. Tubes were mixed gently end over end on a rotary mixer at RT for $2 \mathrm{~h}$. Tubes were washed 3 times in $1 \mathrm{~mL}$ of sterile PBS per wash on the MPC ${ }^{\circledR}$ magnetic rack with $\mathrm{MB}$ resuspension in $\mathrm{PBS}$ following magnetic collection for 2 min. Captured GHRPs and other molecules were eluted off of the aptamer-MBs by resuspension of the aptamer-MBs in $50 \mu \mathrm{L}$ of $0.1 \mathrm{M} \mathrm{HCl}$ for $5 \mathrm{~min}$ at RT. Aptamer-MBs were again collected for $5 \mathrm{~min}$ on the $\mathrm{MPC}^{\circledR}$ magnetic rack and the eluate was siphoned out with a pipette tip and transferred to a fresh microfuge tube. The $\mathrm{pH}$ of the eluate was neutralized with 50 $\mu \mathrm{L}$ of $0.1 \mathrm{M} \mathrm{NaOH}$ [15].

\section{Electrophoresis, gel staining and mass spectrometry}

Twenty $\mu \mathrm{L}$ of each pull down sample were mixed with $20 \mu \mathrm{L}$ of Invitrogen Novex ${ }^{\circledR}$ 5X TBE (Tris-Borate-EDTA) sample loading buffer and electrophoresed in various wells of $20 \%$ polyacrylamide TBE gels at $200 \mathrm{~V}$ in cold $1 \mathrm{X}$ TBE buffer for $1 \mathrm{~h}$ followed by Coomassie Blue staining (Invitrogen Simply Blue ${ }^{\mathrm{TM}}$ stain) and/or Invitrogen SilverQuest ${ }^{\mathrm{TM}}$ silver staining according to the manufacturer's instructions. Gels were also loaded with 7-10 $\mu \mathrm{L}$ of ColorBurst ${ }^{\mathrm{TM}}$ (8-220 kD; Sigma Chemical Co., St. Louis, MO, Cat. No. C1992) or Spectra ${ }^{\mathrm{TM}}$ Multicolor Low Range (1.7-40 kD; Thermo-Fisher, Cat. No. 26628) MW markers for reference to the probable relative MWs of detected bands. The remaining $80 \mu \mathrm{L}$ of each eluted and $\mathrm{pH}$-neutralized sample were sent on ice to the core mass spectrometry laboratory at the University of Texas Health Science Center at San Antonio (UTHSCSA) for electrospray ionization time-of-flight (ESI-TOF) mass spectrometry analysis by comparison with the $>98.0 \%$ purified standard AA-3 and G6 stock peptide samples.

\section{Results and Discussion}

Table 1 reveals the DNA sequences of the top four lead aptamer candidates as determined by extensive ELASA screening and ranking of the highest affinity (darkest green or highest Absorbance at $405 \mathrm{~nm}$ ) candidates from among the 142 total aptamer candidates for AA-3 and G6 aptamers (ELASA screening data not shown for brevity). From Table 1, it appears that runs of multi- 


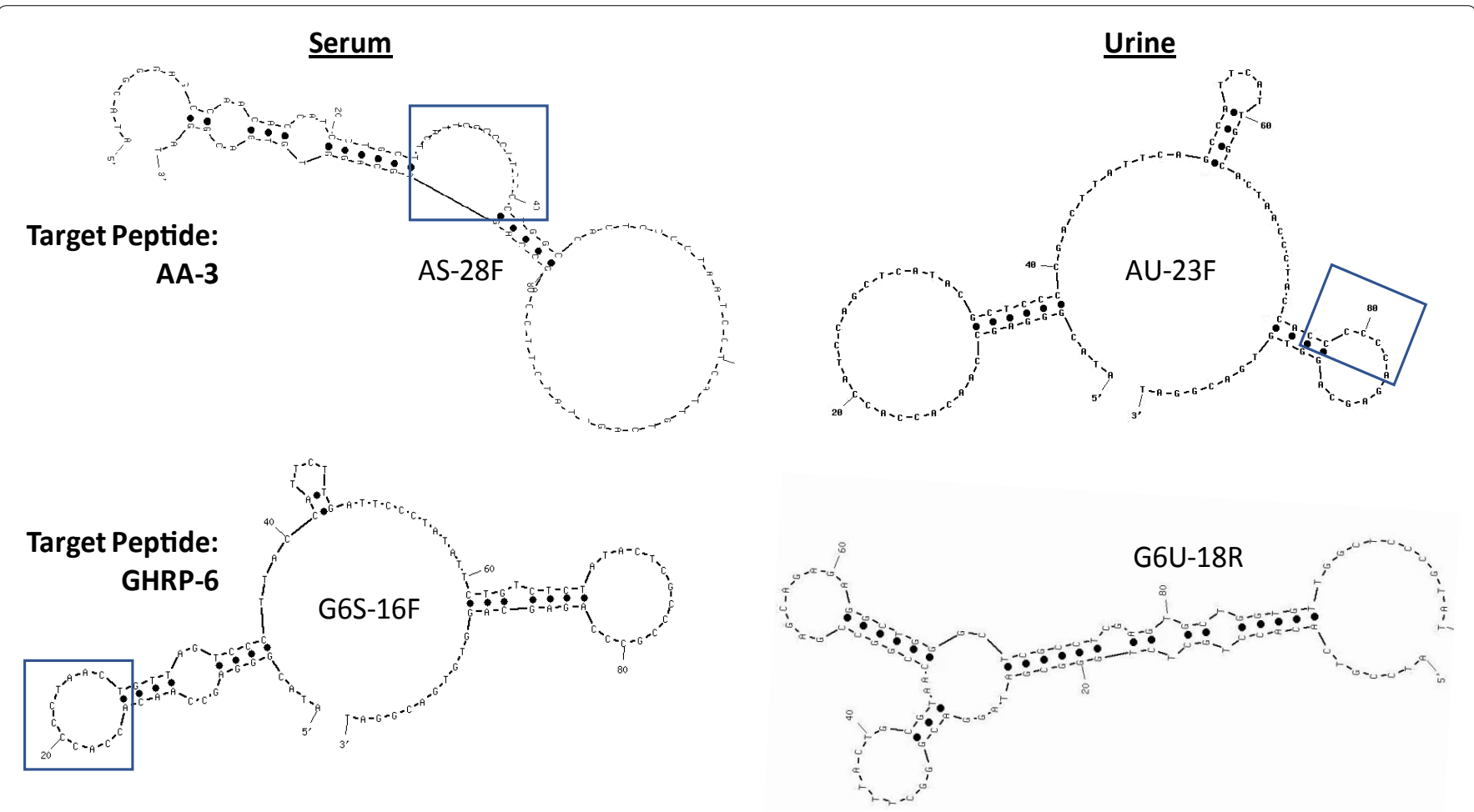

Figure 2: Secondary stem-loop structures of the lead GHRP aptamers generated by use of free internet UNAFold software using $145 \mathrm{mM} \mathrm{Na}^{+}$and $25^{\circ} \mathrm{C}$. The highest affinity (lowest $\Delta \mathrm{G}$ ) structures are shown in each case. Boxed regions indicate $\mathrm{C}$ and T-rich regions from Table 1 which also form loop regions in the 2-dimensional structures and may be favorable areas for GHRP binding.

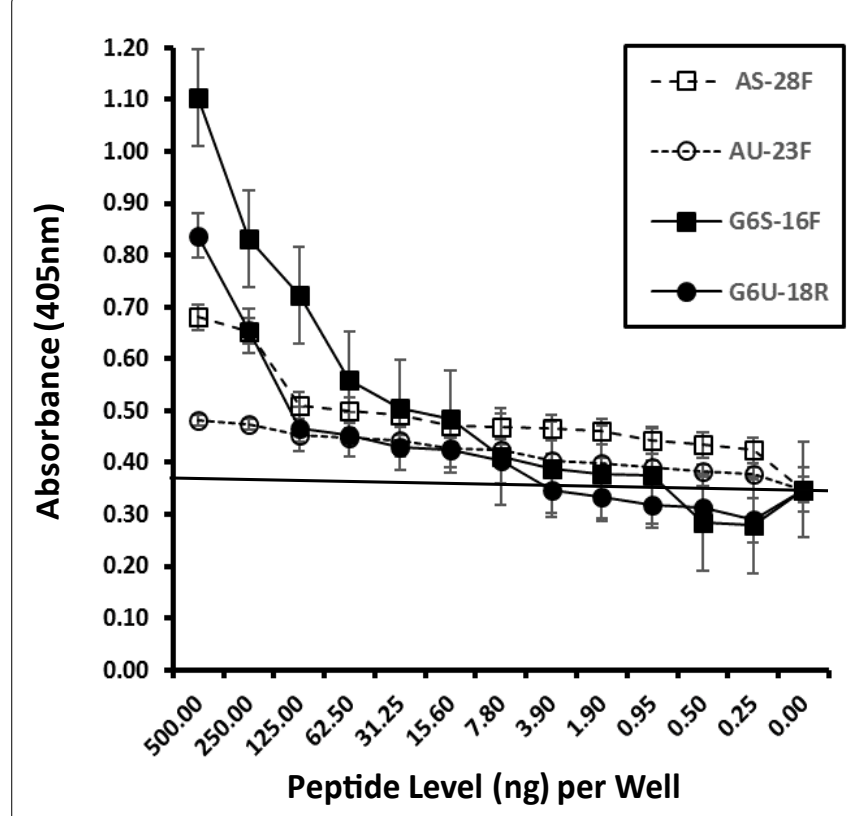

Figure 3: Results of different titration trials for the direct $A A-3$ and $G 6$ enzyme-linked sandwich assays (ELASAs) using the lead aptamers from Table 1 or Figure 2 in PBS. Means and standard deviation error bars for three independent trials $(N$ $=3$ ) are shown. The dotted line indicates the baseline mean for the background absorbance at $405 \mathrm{~nm}$ level without aptamers. Results from human serum and urine ELASA titrations (not shown) were flat perhaps due to larger proteins adhering to the wells and preventing aptamer binding.

ple cytosines $(C)$ flanked by one or more thymines $(T)$ in three of the lead candidates excluding the constant 18base PCR primer regions (italicized) on the $5^{\prime}$ and $3^{\prime}$ ends was a common finding, although other shared sequence runs between the candidates appeared to be present as well. The notion that some of these high $C$ and $T$ content regions could be binding regions for the GHRPs was supported by the secondary structural analyses generated by UNAFold shown in Figure 2 where runs of multiple Cs flanked by Ts are noted in the boxed regions.

Figure 3 illustrates that while the $\mathrm{G} 6$ aptamers developed in serum (G6S-16F) and urine (G6U-18R) in their designations) appeared to have significantly higher affinity than the AA-3 aptamers (AS-28F and AU-23F), three of the four lead aptamers appeared to have limits of detection in the mid to low nanogram per well ranges (i.e., remained above the mean background level indicated by the dotted line) when tested by ELASA in PBS. All four titration curves completely flattened out in human serum and urine (body fluid data not shown because it was flat in all cases). This failure to detect AA-3 or GHRP- 6 in serum and urine by ELASA could be due to much larger proteins from the body fluid samples adhering to and obscuring the immobilized small peptides (AA-3 or G6) on the surface of the wells, but this failure may be specific to the ELASA surface detection methodology and appeared to be overcome by the use of aptamer-coated magnetic beads and pull down methodology $[14,15]$.

Figure 4 Illustrates that all four lead aptamers appeared to pull down their cognate target peptides in buffer (PBS) spiked with $100 \mu \mathrm{g}$ of AA-3 or G6 when the biotinylated aptamers were bound to $100 \mu \mathrm{L}$ of stock streptavidin-MBs (lanes 2-5) especially when compared 


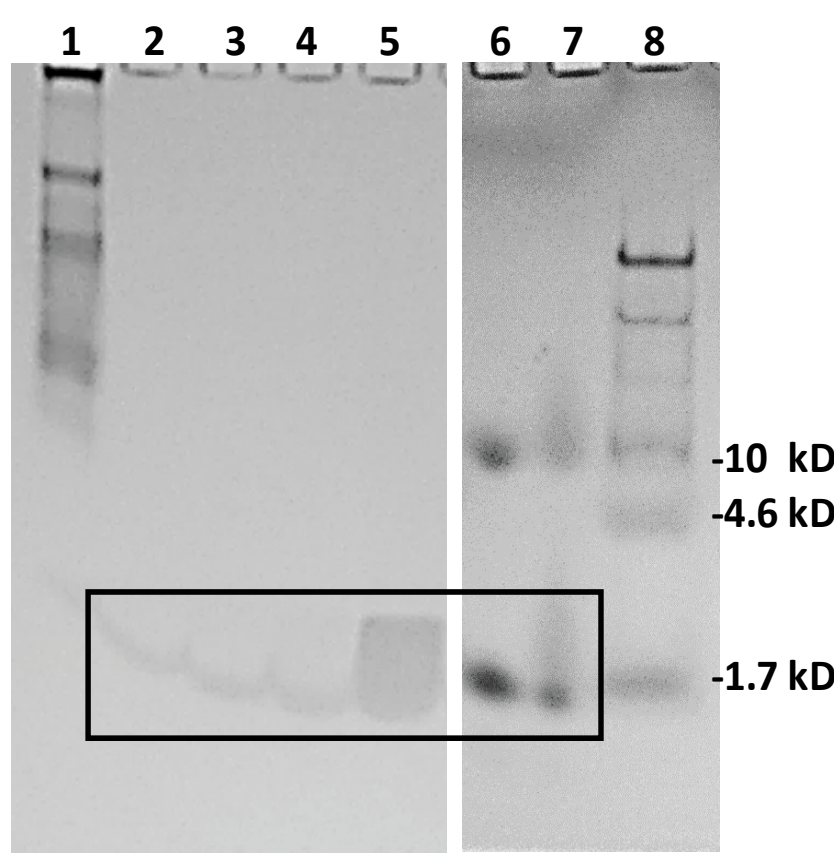

Figure 4: Coomassie blue-stained $20 \%$ polyacrylamide gel electrophoresis results from the aptamer-MB pull down conducted in buffer (PBS). Lane 1: $7 \mu \mathrm{L}$ of 8-220 kD Sigma ColorBurst ${ }^{\mathrm{TM}} \mathrm{MW}$ markers; lane 2: $20 \mu \mathrm{L}$ of eluted pull down material from the AS-28F aptamer-MBs; lane 3: $20 \mu \mathrm{L}$ of eluted pull down material from the AU-23F aptamer-MBs; lane 4: $20 \mu \mathrm{L}$ of eluted pull down material from the G6S-16F aptamer-MBs; lane 5: $20 \mu \mathrm{L}$ of eluted pull down material from the G6U-18R aptamer-MBs; lane 6: $2 \mu \mathrm{g}$ of AA-3 standard peptide; lane 7: $2 \mu \mathrm{g}$ of GHRP-6 (G6) standard peptide and lane 8: $10 \mu \mathrm{L}$ of Thermo-Fisher Spectra ${ }^{\mathrm{TM}}$ Multicolor Low Range (1.7-40 kD) MW markers. Lanes 6-8 were run in a separate $20 \%$ polyacrylamide gel under identical conditions. The boxed region encloses faint, but detectable, bands suggesting detection of the AA-3 and $\mathrm{G} 6$ peptides.

to $2 \mu \mathrm{g}$ standards of the AA-3 (lane 6) and G6 (lane 7) peptides (boxed region for lanes 2-7) after Coomassie blue staining. The gel in Figure 4 does contain some anomalies such as the diffuse band for $\mathrm{G} 6$ pulldown with G6U-18R in lane 5 and the higher $10 \mathrm{kD}$ bands in lanes 6 and 7 for the peptide standards as well as the smear in the boxed region of lane 7. Some of these anomalous results may be attributable to charge effects and aggregate formation due to the lack of sodium dodecyl sulfate (SDS) in the gel or samples to equalize all charges across the board. The authors wished to use SDS for more precise MW determinations. However, when SDS was added in other gel electrophoresis experiments (gels not shown), it appeared to eliminate detection of the putative peptides by Coomassie blue staining.

The gel image in Figure 5 illustrates the lack of detection of the very low MW peptide bands when the aptamer-MB pull down was conducted in human serum spiked with $100 \mu \mathrm{g}$ of AA-3 or G6 and the $20 \%$ polyacrylamide gel was Coomassie blue stained. However, interestingly, two clear bands of a protein or proteins with apparent $\mathrm{MW}$ of $\sim 50 \mathrm{kD}$ were pulled down from human serum by the two $\mathrm{G} 6$ aptamers (lanes 4 and 5 of Figure 5).

Staining of the same gel shown in Figure 5 with the

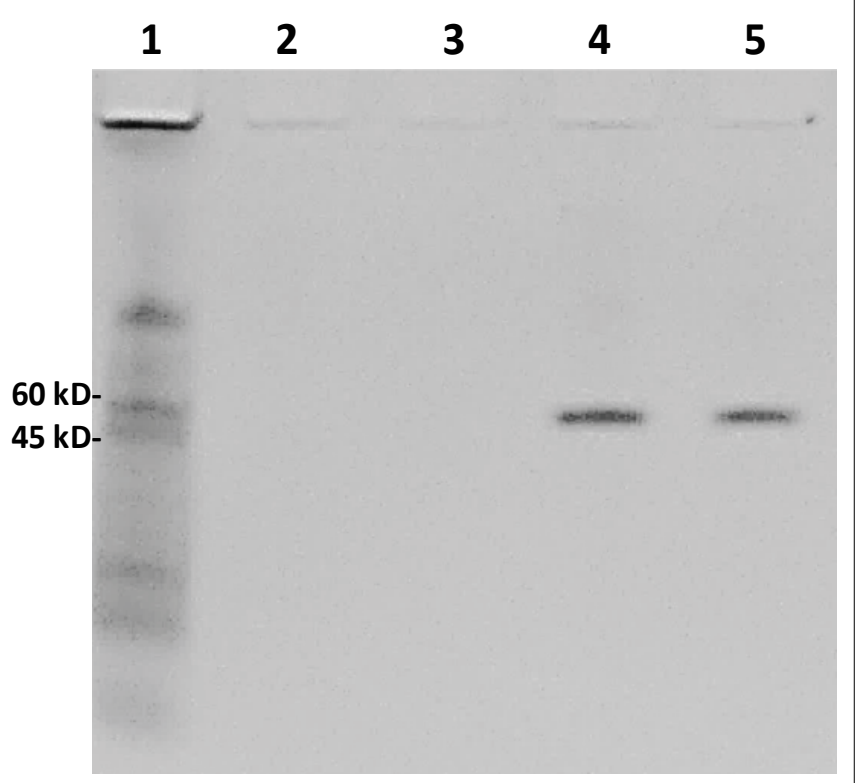

Figure 5: Another Coomassie blue-stained 20\% polyacrylamide electrophoresis gel from the aptamer-MB pull down conducted in human serum. Lane 1: $7 \mu \mathrm{L}$ of 8-220 kD Sigma ColorBurst $^{\mathrm{TM}} \mathrm{MW}$ markers; lane 2: $20 \mu \mathrm{l}$ of eluted pull down material from the AS-28F aptamer-MBs; lane 3: $20 \mu \mathrm{L}$ of eluted pull down material from the AU-23F aptamer-MBs; lane 4: $20 \mu \mathrm{L}$ of eluted pull down material from the G6S16F aptamer-MBs; lane 5: $20 \mu \mathrm{L}$ of eluted pull down material from the G6U-18R aptamer-MBs. Although no low MW peptide bands are seen with Coomassie blue staining, clear $\sim 50 \mathrm{kD}$ protein bands were pulled down by the G6S-16F and G6U-18R aptamers (lanes 4 and 5) from human serum.

more sensitive silver stain demonstrates that very low MW bands do appear in Figure 6A lanes 2-5 (boxed) which may correspond to AA-3 and G6 peptides. These same low MW bands, however, are not seen in the adjacent gel image (Figure 6B) from aptamer-MB pull down samples obtained from human urine spiked with $100 \mu \mathrm{g}$ of AA-3 or G6. A number of higher $\mathrm{MW}$ bands do appear which derive from serum and urine when stained with the more sensitive silver stain indicating that trace levels of other proteins probably nonspecifically adhere to the aptamer-MBs.

While electrophoresis of the supposed low MW peptides in Coomassie blue or silver stained polyacrylamide gels was suggestive of some successful aptamer-MB pull down, the ultimate test to validate pull down of the AA-3 and $\mathrm{G} 6$ was to detect and identify these peptides by MS in buffer, human serum and human urine. The results of this effort with the UTHSCSA's Mass Spectrometry Core Laboratory are summarized in Table 2 which gives the results of four separate trials using either $100 \mu \mathrm{L}$ (Trial 1) or $500 \mu \mathrm{L}$ (Trials 2-4) of aptamer-MBs in PBS, human serum or urine. In Table 2, the plus symbol represents positive detection at any signal intensity and the minus symbol represents the inability to detect a given target peptide by ESI-TOF MS, albeit the qualifier (low + ) was used to indicate a barely perceptible G6 peptide peak in one case. The Table does not document the results of negative control studies in which streptavidin-MBs alone were added to $100 \mu \mathrm{g}$ of AA-3 or G6 spiked into 
A. Pull Down from Serum

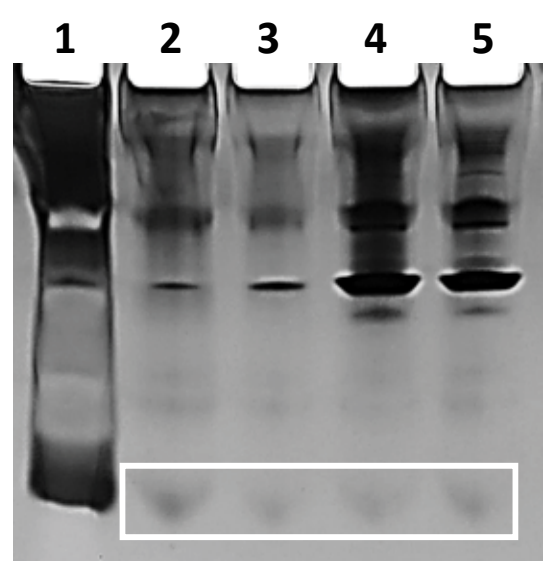

B. Pull Down from Urine

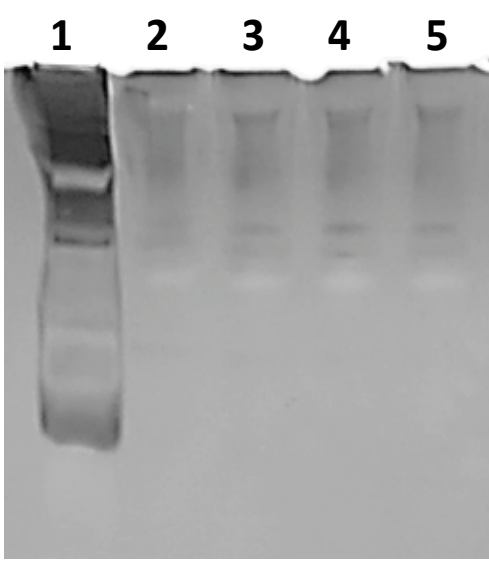

Figure 6: Panel A) The same gel shown in Figure 5 following fixation and silver staining. The boxed region may enclose the low MW AA-3 and G6 peptides which were not visible with the less sensitive Coomassie blue stain in Figure 5; Panel B) A similar $20 \%$ polyacrylamide gel electrophoresis result for the same aptamer-MB pull down assay scheme described and conducted in Figure 5 but in human urine instead of serum. No low MW peptide bands were observed for the pull down assay from urine despite the more sensitive silver staining.

Table 2: Summary of Aptamer-MB pull down experiments using mass spectrometry detection.

Trial 1: Buffer $+100 \mu \mathrm{l}$ of Aptamer-MBs

\begin{tabular}{|c|c|c|c|c|}
\hline Target & AA-3 & AA-3 & GHRP-6 & GHRP-6 \\
\hline Aptamer & AS-28F & $A U-23 F$ & G6S-16F & G6U-18R \\
\hline Detection & + & + & - & low + \\
\hline \multicolumn{5}{|c|}{ Trial 2: Buffer $+500 \mu$ l of Aptamer-MBs } \\
\hline Target & AA-3 & AA-3 & GHRP-6 & GHRP-6 \\
\hline Aptamer & AS-28F & AU-23F & G6S-16F & G6U-18R \\
\hline Detection & + & + & + & - \\
\hline \multicolumn{5}{|c|}{ Trial 3: Serum $+500 \mu l$ of Aptamer-MBs } \\
\hline Target & AA-3 & AA-3 & GHRP-6 & GHRP-6 \\
\hline Aptamer & AAS-28F & AAU-23F & G6S-16F & G6U-18R \\
\hline Detection & + & + & + & - \\
\hline \multicolumn{5}{|c|}{ Trial 4: Urine $+500 \mu \mathrm{l}$ of Aptamer-MBs } \\
\hline Target & AA-3 & AA-3 & GHRP-6 & GHRP-6 \\
\hline Aptamer & AAS-28F & AAU-23F & G6S-16F & G6U-18R \\
\hline Detection & + & + & + & + \\
\hline
\end{tabular}

Notes: (+): Successful detection of the subject peptide by MS at any level; (-): No target peptide detection by MS and (+ low): Barely perceptible peak for the subject peptide. Negative control results employing streptavidin (SAv)-MBs without aptamers are not shown in the table, but were negative (i.e., failed to show any evidence of AA-3 or GHRP-6 adhering to SAv-MBs by MS when buffer was spiked with $100 \mu \mathrm{g}$ of AA-3 or GHRP-6 and the pull down assay was conducted without biotinylated aptamers on the SAv-MBs).

PBS, human serum or urine, but these negative controls did not produce any perceptible peptide peaks (i.e., the negative controls were negative).

Analysis of the three failures (-) and one dubious (low + ) result in Table 2 reveals that they occurred when either the lesser $100 \mu \mathrm{L}$ amount of aptamer-MBs was used or the aptamer used was not developed in the environment in which it was used. Thus, increasing to $500 \mu \mathrm{L}$ of aptamer-MBs enabled G6S-16F to achieve positive detection of GHRP-6 (compare Trials 1 and 2). This was not the case for the G6U-18R aptamer when the level of aptamer-MBs was increased from 100 to $500 \mu \mathrm{L}$ in PBS, in fact detection went from barely perceptible to negative (compare Trials 1 and 2 for G6U-18R). Detection using $500 \mu \mathrm{L}$ of G6U-18R in serum also failed but changed to successful positive detection in urine (Trial 4 of Table 2 for G6U-18R). This observation strongly suggests that the G6U-18R aptamer must be in a higher urea concentration or at least in the urine milieu in order to fold into the correct conformation to bind and detect GHRP-6. Bruno observed similar chemical environmental effects on a cancer biomarker aptamer (ERK2) in previous work in which $2 \mathrm{mM}$ EDTA was added to bind any free divalent cations (to mimic the diluted blood environment in which the aptamer) was selected. The removal of divalent cations was required to make the ERK2 aptamer fold properly, bind and pull down ERK2 [15]. No quantitative or semi-quantitative data were obtained by $\mathrm{MS}$, because this would require costly studies, although one can surmise that detection levels of the AA-3 and G6 peptides were low since it is known that ESI-TOF MS can detect sub-ng levels of peptides $[5,6]$.

\section{Conclusions}

The data presented herein represent a first attempt 
to develop DNA aptamers capable of binding and pulling down GHRPs in body fluids to detect athletes who are doping with these hGH secretagogues. The data are generally encouraging and suggest that optimization such as determining the exact optimal level of aptamer-MBs to add to a given sample volume should be the next step in assay development. While it is true that relatively large amounts of the target peptides $(100 \mu \mathrm{g}$ each) were spiked into the buffer, serum and urine samples, the surface area of aptamer-coated MBs is probably relatively small for capture of the abundant $100 \mu \mathrm{g} /$ $\mathrm{mL}$ targets, thus leading to low levels of pulled down target materials. It is, however, certain that aptamer pull down is specific since the use of simple streptavidin-coated MBs without the tethered aptamers (negative controls) failed to detect AA-3 or G6 peptides by MS (data not shown). Interestingly, the two G6 aptamers (G6S-16F and G6U-18R) whether developed in diluted $10 \%$ serum (S) or $50 \%$ urine (U) clearly pulled down a protein from serum in the range of $\sim 50 \mathrm{kD}$. Analysis using the University of Delaware's Protein Information Resource database and Peptide Match search engine [16] produced zero hits when the full GHRP-6 peptide sequence (HWAWFK) or truncated versions of the GHRP-6 sequence such as HWAWF or WAWFK were used as search terms. However, the partial sequence WAWF produced over 30 hits within the human proteome and one in particular for human heavy chain Fab antibody fragments (e.g., http://www.uniprot.org/uniprot/A2NYU6) which is very plausible to find in human serum and might weigh $~ 50 \mathrm{kD}$, if degraded, although numerous other serum proteins are possible interferents. This observation of competitive interference from serum proteins (bands in lanes 4 and 5 of Figure 5) while problematic for detection of GHRP-6 in serum, does also attest to the specificity of the G6 aptamers. And if the target for these G6 aptamers is truly WAWF, then the authors may be able to find other aptamers among their final pool of 73 candidate $G 6$ aptamers that can bind the histidine $(\mathrm{H})$ or lysine $(\mathrm{K})$ ends of GHRP-6 (HWAWFK) for enhanced specificity in serum samples.

Finally, it is interesting to note from Table 2 that increasing the level of aptamer-MBs from 100 to $500 \mu \mathrm{L}$ helped one of the mass spectral analyses for the G6S$16 \mathrm{~F}$ aptamer to achieve detection (i.e., to become positive between Trials 1 and 2 in PBS), presumably due to the $5 \mathrm{X}$ increased surface area provided by five times more MBs. And it is interesting that the G6U-18R aptamer either failed or performed marginally in Table 2 unless it was placed in urine, the environment in which it was selected. This fact, strongly suggests that the aptamer folding can be influenced by high urea levels or other chemical factors such as divalent cation concentration as Bruno observed in a separate aptamer-MB pull down study [15]. These observations also underscore the importance of selecting and developing aptamers in a chemical milieu as close as possible to the environment or body fluid in which the aptamers are intended to be used.

While, the presently reported aptamers may never actually be used to detect athlete doping with GHRP2 or -6 , they illustrate the potential of aptamers to detect small peptides and other analytes in magnetic pull down assays where antibodies may fail due to the lack of peptide immunogenicity during development in vivo. In addition, aptamers can be developed faster and less expensively than antibodies without the use of animals or cell culture. Thus, aptamers are reagents that magnetic bead analyte separation techniques including those coupled to MS detection such as SISCAPA (Stable Isotope Standards and Capture by Anti-Peptide Antibodies) [17-20] may wish to consider along side or in lieu of antibodies for small analyte detection in body fluids.

\section{Acknowledgments}

This work was funded by World Anti-Doping Agency (WADA) Grant No. 16B02JB. The authors are grateful to the Core Mass Spectrometry Laboratory at the Univ. of Texas Health Sciences Center at San Antonio, especially Mr. Sam Pardo, for contracted mass spectrometry and consultation.

\section{References}

1. Bruno JG, Carrillo MP, Phillips T, Edge A (2011) Discrimination of recombinant from natural human growth hormone using DNA aptamers. J Biomolec Techn 22: 27-36.

2. Bruno JG, Richarte AM (2016) Development and characterization of an enzyme-linked DNA aptamer-magnetic beadbased assay for human IGF-I in serum. Microchem $\mathrm{J} 124$ : 90-95.

3. McDowell RS, Elias KA, Stanley MS, Burdick DJ, Burnier JP, et al. (1995) Growth hormone secretagogues: characterization, efficacy, and minimal bioactive conformation. Proc Natl Acad Sci USA 92: 11165-11169.

4. Barroso O, Handelsman DJ, Strasburger C, Thevis $M$ (2012) Analytical challenges in the detection of peptide hormones for anti-doping purposes. Bioanalysis 4: 1577-1590.

5. Okano M, Sato M, Ikekita A, Kageyama S (2010) Determination of growth hormone secretagogue pralmorelin (GHRP-2) and its metabolite in human urine by liquid chromatography/electrospray ionization tandem mass spectrometry. Rapid Commun Mass Spectrom 24: 2046-2056.

6. Thomas A, Höppner S, Geyer H, Schänzer M, Petrou M, et al. (2011) Determination of growth hormone releasing peptides (GHRP) and their major metabolites in human urine for doping controls by means of liquid chromatography mass spectrometry. Anal Bioanal Chem 401: 507-516.

7. Kwok WH, Ho EN, Lau MY, Leung GN, Wong AS, et al. (2013) Doping control analysis of seven bioactive peptides in horse plasma by liquid chromatography-mass spectrometry. Anal Bioanal Chem 405: 2595-2606.

8. Thomas A, Geyer H, Kamber M, Schänzer W, Thevis $M$ (2008) Mass spectrometric determination of gonadotrophin-releasing hormone $(\mathrm{GnRH})$ in human urine for doping control purposes by means of LC-ESI-MS/MS. J Mass Spectrom 43: 908-915.

9. Jayasena SD (1999) Aptamers: An emerging class of mol- 
ecules that rival antibodies in diagnostics. Clin Chem 45: 1628-1650.

10. Perkel JM (2013) The antibody challenge. Biotechniques 56: 111-114.

11. Bordeaux J, Welsh A, Agarwal S, Killiam E, Baquero M, et al. (2010) Antibody validation. Biotechniques 48: 197-209.

12. Bruno JG, Carrillo MP, Phillips T, Hanson D, Bohmann JA (2011) DNA aptamer beacon assay for C-telopeptide and handheld fluorometer to monitor bone resorption. J Fluorescence 21: 2021-2033.

13. Bruno JG, Richarte AM, Phillips T (2014) Preliminary development of a DNA aptamer-magnetic bead capture electrochemiluminescence sandwich assay for Brain Natriuretic Peptide. Microchem J 115: 32-38.

14. Kim K, Lee S, Ryu S, Han D (2014) Efficient isolation and elution of cellular proteins using aptamer-mediated protein precipitation assay. Biochem Biophys Res Comm 448: 114-119.

15. Bruno JG (2017) Effects of various additives on cancer biomarker aptamer-magnetic pull-down in human serum. $J$ Bionanosci 11: 45-51.
16. Chen C, Li Z, Huang H, Suzek BE, Wu CH (2013) A fast peptide match service for UniProt knowledge base. Bioinformatics 29: 2808-2809.

17. Anderson NL, Anderson NG, Haines LR, Hardie DB, Olafson RW, et al. (2004) Mass spectrometric quantitation of peptides and proteins using Stable Isotope Standards and Capture by Anti-Peptide Antibodies (SISCAPA). J Proteome Res 3: 235-244.

18. Anderson NL, Jackson A, Smith D, Hardie D, Borchers C, et al. (2009) SISCAPA peptide enrichment on magnetic beads using an in-line bead trap device. Mol Cell Proteomics 8: 995-1005.

19. Schoenherr RM, Zhao L, Whiteaker JR, Feng C, Li L, et al. (2010) Automated screening of monoclonal antibodies for SISCAPA assays using a magnetic bead processor and liquid chromatography-selected reaction monitoring-mass spectrometry. J Immunol Methods 353: 49-61.

20. Kuhn E, Carr SA (2016) Multiplexed immunoaffinity enrichment of peptides with anti-peptide antibodies and quantification by stable isotope dilution multiple reaction monitoring mass spectrometry. Methods Mol Biol 1410: 135-167. 